\title{
تحليل وقياس العجز المزدوج في الإقتصادات النفطية دراسة حالة العراق للمدة (1988-2016)
}

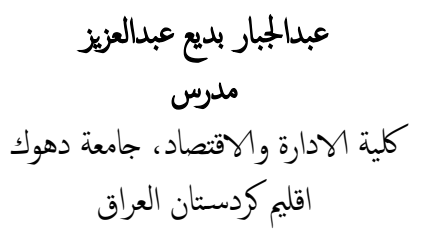

عبدالجبار بديع عبدالعزيز

كلية الودارة والاقتصاد، جامعة دهوك

اقليم كردستان العراق

\author{
ماهر عمر علي

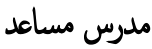 \\ قسم الاقتصاد، جامعة نوروز \\ اقليم كزدستان العراق
}

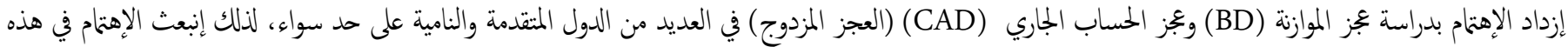

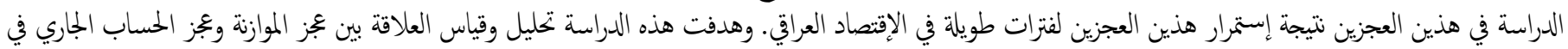

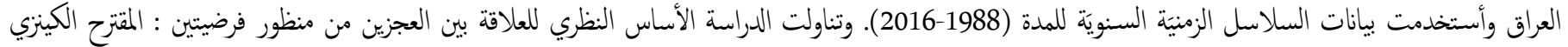

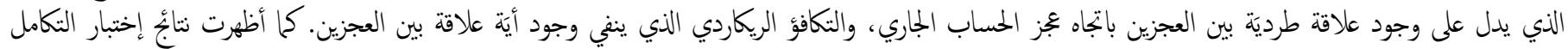

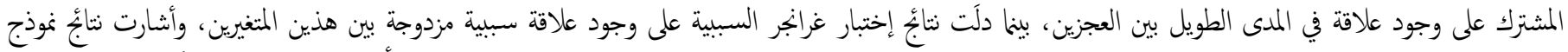

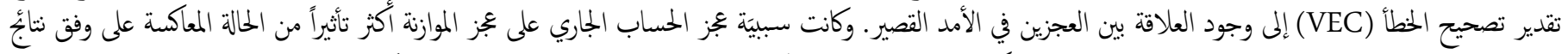

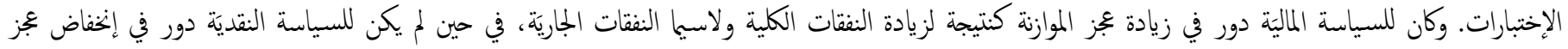

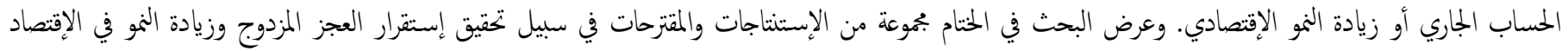

الكلمات الدالة : العجز المزدوج، عجز الموازنة، جز الحساب الجاري، المقتح الكينزي، التكمل المشترك ونوذج تصحيح الخطأ (VEC).

1

من مشاكل إقتصادية مزمنة أعاقت مسيرة التنمية وأدت إلى إختلالات هيكلية في أداء تلك الإقتصادات، وكذلك الدول النفطية، ومنها العراق، فقد حققت عبر إرتفاع عوائدها النفطية (خاصةً بين الفترة 2004-2014) فوائض كبيرة في موازنة حكومتها وفي ميزان مدفوعاتها على حد سواء، ولكن تلك الفوائض المؤتنة ما لبثت أن تحولت إلى جوزات أضرت بإقتصاد العراق وأثرت على مسيرته التنموية وأدائه ونشاطه الإقتصادي، فقي فترة العجوزات خلال المدة (1988-2004) بلغت متوسطات جز الحساب الجاري والموازنة العامة حوالي (298. 8 \% و 69. 4 \%) على التوالي، والفزتة (2005-2016) بلغت (1. 07 \% و 4. 04 \%) على التوالي، نلاحظ من ذلك أن فترة ججز الحساب الجاري خلال مدة الدراسة بلغت (19 سنة) من اصل (29 سنة) اي (267\%)، بينا جزز الموازنة بلغ (17 سنة) أي (56\%)، ما يتبين ضخامة ججم العجوزات في الإقتصاد العراقي. لذلك يعد إقتصاد العراق أحادي الجانب، إذ أن أغلب إيرادات الموازنة تعتمد على مصدر واحد وهو النفط وهذا ما ييجل الإقتصاد عرضةً للتقلبات الخارجية، بالإضافة إلى أن صادرات الدولة إلى الخارج تعتمد كلياً على ذلك المصدر مما ينعكس أثر ذلك على رصيد الحساب الجاري نتيجة عجز
إعتاد الحكومات على السياسة المالية، من أجل تحقيق الأهداف الإقتصادية لتحقيق الإستقرار والنمو، كان جانباً مشتركاً للعديد من البلدان المتقدمة نمواً والنامية على مر الزمن، وكان مصحوباً مع هذه الحكومات في معظم الحالات العجز الملالي الكبير. لذلك واحدة من أهم المناقشات الإقتصادية الحالية هي طبيعة العلاقة بين السياسة المالية والحساب الجاري. وقد برزت أهمية هذا الموضوع عندما شهدت فترة الثانينات من القرن العشرين في الولايات المتحدة الأمريكية عجزاً في كل من موازتها العامة وميزان مدفوعاتها، وهو ما أطلق عليه تسمية العجز التوأم، وكذلك من خلال الزيادة المطردة في العجز النجاري الأمريكي إلى حوالي (6\%) من الناجت المحلي الإجلالي (GDP) في عام 2008، والتأربح الأخير في الميزان المالي الأمريكي من الفائض إلى العجز الكبير. وقد إستمرهذين العجزين لفترات طوياة في العديد من الدول النامية، ومعاناة إقتصاداتها

المجلة الاكاديمية لجامعة نوروز, المجلد 8, العدد 1 (2019)

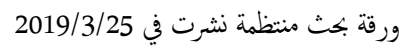

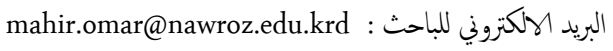
حقوق الطبع والنشر (C) 2017 أسماء المؤلفين. هذه مقالة الوصول اليها مفتوح موزعة تحت رخصة

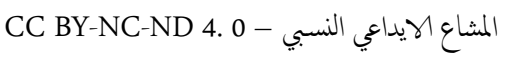


العجزين في الأمدين القصير والطويل، وتختلف طبيعة هذه العلاقة بين إقتصادات الدول النفطية عن غيرها من الإقتصادات المتقدمة والإقتصادات النامية غير النفطية، ذلك وفقا لطبيعة السياسة الإقتصادية المتبعة في الدولة.

\section{5}

يعتمد البحث على الإسلوب الوصفي التحليلي في الجانب النظري والإسلوب الإحصائي القياسي في الجانب العملي، وذلك بإستخدام طرق قياسية حديثة.

2. التأصيل النظري لفرضية العجز المزدوج والدراسات السابقة 2.1

\subsection{1 الربط بين جزز الموازنة العامة والحساب الجاري من خلال مثطابقة الدخل المحلي}

المبرر الإقتصادي للعلاقة ما بين عجز الموازنة العامة والحساب الجاري من المتمل آن يعود إلى متطابة الدخل المحلي (الناجت المحلي الإجلالي)، والتي تعتبر أساساً نظرياً لدراسة العلاقة بين العجزين (Çelik \& Deniz,2007, 3) وهي كالتالي :

$$
y=C+I+\text { + }+(\text { (EX - IM) ............. (1) 2001، 7-5). }
$$

عندما (G ، ، ، ، C كدخل محلي، الإستهلاك العائلي، الإنفاق الإستثاري، والإنفاق الحكوي على التوالي بينا EX و تمثل الصادرات (الإستهلاك الخارجي)

$$
\text { والإستيرادات (الإستهلاك المحلي) للسلع والخدمات على التوالي. }
$$

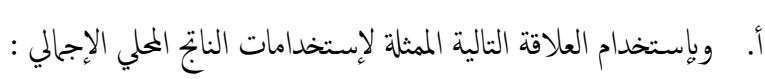

$$
\mathrm{y}=\mathrm{C}+\mathrm{S}+\mathrm{T}
$$

ب. وبتساوي المعادلتين (1) و (2) بعد حذف الإستهلاك من الطرفين نحل على :

$$
I+G+E X-I M=S+T
$$

$$
(E X-I M)=(S-I)+(T-G)
$$

$$
\mathrm{TD}=\mathrm{SD}+\mathrm{BD}
$$

حيث يشير المقدار Td = (EX - IM) إلى الفرق بين الصادرات والواردات من السلع والخدمات أو ما يسمى بعجز الميزان التجاري (Trade deficit). ويمثل المقدار SD = (S - I) إلى الفرق بين الإدخار والإستثمار الخاص او ما يسمى بصافي الإدخار الخاص او عجز الإدخار (Saving deficit). والمقدار (T - B = هو الفرق بين إيرادات ونفقات الدولة أو ما يسمى بعجز الموازنة (Budget deficit).
الميزان التجاري. وقد تعرض الإقتصاد العراقي منذ الثانينيات الذي شهد إنهيار في أسعار البترول إلى ظاهرة العجزين في الموازنة العامة والحساب الجاري، لذلك تأتي أهية هذا البحث لتناول العلاقة بين العجزين في إقتصاد نفطي بسبب أختلاف ظروف وأداء الإقتصادات النفطية عن غيرها من الإقتادات المتقدمة والإقتصادات النامية غيرالنفطية. 1.1

تعرض الإقتصاد العراقي إلى إختلالات هيكلية وآثار سلبية جراء إستمرار هذين العجزين منذ أمد بعيد، لذا تأتي أهية البحث من ما أكتسبت الموازنة العامة للدولة ورصيد الحساب الجاري في ميزان مدفوعاتها دوراً أكثر أهمية وأصبحت الأدوات الرئيسية للندخل الحكوي في الإقتصاد، ومعالجة ما يتعرض له من هزات وأزمات مالية. فضلاً عن ما لها من أثر على التنمية، ووسيلة لتحقيق أهدافها الاقتصادية.

\section{2}

عانى الإقتصاد العراقي منذ زمن بعيد من ظاهرة العجز المزدوج المتمثلة في جز الموازنة العامة وجز الحساب الجاري والتي أدت إلى حدوث إختلالات في الهيكل الإقتصادي، مما تبين أن جذور حالتي العجز في الإقتصاد العراقي تكمن في الهيكل الإقصادي الذي يتسم بمستوى إستيعاب محلي يفوق كثيراً مستوى الإنتاج المحلي. من هذا المنظور فإن إثكلية الدراسة تكمن في التساؤلات الآتية : 1. ما هو أثرعلاقة جزز الموازنة العامة (عدم التوازن الداخلي) بعجز الحساب الجاري (عدم التوازن الخارجي) وبالعكس في العراق خلال الفترة (1988-2016)؟ 2. في حالة وجود العلاقة بينها، ماهو إتجاه السببية بنيها؟ ولأي السياسات تعطي الأولوية، هل للسياسة المالية (الداخلية) أم لسياسة التجارة الخارجية أو لكليها؟

1.3 أهداف البحث تسعى هذه الدراسة إلى تحقيق عدة أهداف : 1. التأكد على وجود علاقة طردية وسبية مزدوجة ما بين عجز الموازنة العامة ويجز الحساب الجاري في الأجلين القصير والطويل. 2. قياس وتحليل العلاقة بين العجزين (الحساب الجاري والموازنة). 3. دراسة التذبذبات في أسعار النفط العالمية وأثرها على العجزين.

1.4 فرضية البحث ينطلق البحث من فرضية مفادها، أن هناك علاقة طردية وسببية مزدوجة الإتجاه بين 


$$
\mathrm{S}+\mathrm{T}+\mathrm{TRnet}=\mathrm{I}+\mathrm{G}+(\mathrm{X}-\mathrm{M})
$$

$(\mathrm{S}-\mathrm{I})+(\mathrm{T}-$

$\mathrm{G})+$ TRnet $=(\mathrm{X}-$

وبترتيب المعادلة خصل

$$
(X-M)+\text { TRnet }=(S-I)+(T-G)
$$

$\mathrm{CAD}$ $=\mathrm{SD}+$

$\mathrm{BD}$

حيث نلاحظ من المعادلات السابقة أن حدوث العجز في الموازنة سوف يؤدي إلى حدوث العجز في الحساب الجاري وبالعكس، وإقتراض ثبات وتوازن الإدخار والإستثار الخاص أو إذا لم تتم معادلنه بزيادة الإدخار عن الإستثمار الخاص. إلا أن ذلك لا يبين إتجاه السبية بين هذين المتغيرين، وبشكل عام أن عجز الحساب الجاري ينتج في حالة إذا كان صافي الإدخار الوطني غير كافي لإستيعاب أو شراء الزيادة في ججم أذونات السندات الحكومية التي قامت بإصدارها لتمويل جزز الموازنة العامة، لكن عجز الحساب الجاري في العراق ينتج عن عجز في الميزان التجاري صادرات العراق تنكون على نسبة كيرة من النفط الخام (القطاع النفطي) تتراوح ما بين (92\% 96\%)، وإن هذه السلع معرضة للصدمات الخارجية وما ينجم عنها من أثار سلبية على ميزان المدفوعات، لذا فإن سبب الإختلال الخارجي لإقتصاد العراق ينشاً من إختلال هيكل الإنتاج فهيا والذي ينتج عن سيادة الإنتاج الأولي. وقد تم إستخدام مصطلح العجز التوأم لحالة التزامن بين جز الحساب الجاري وعزز الموازنة العامة التي أصابت الإقتصاد الأمريكي خلال الفترة (1981-1998). إضافةً إلى بلدان اخرى أعضاء في منظمة التعاون الإقتصادي والتنمية (OECD) تعرضت خلال هذه الفترة إلى العجز التوأم ومن بين هذه الدول استراليا، انكلترا، والمانيا (وردة، 2016، 221). ويسود الفكر الإقتصادي منهجان تفسيريان للعلاقة بين عجز الموازنة ويجز الحساب الجاري : المنهج الكينزي، والنكؤُ الريكاردي.

\section{2 المقتزح الكينزي (Keynesian Proposition)}

العجز المزدوج هو لبنات أفكار المنهج الكينزي الذي يرى أن هنالك علاقة مباثرة تربط بين عجز الموازنة العامة ويجز الحساب الجاري لميزان المدفوعات، ويحدد إتجاه هذه العلاقة من جزز الموازنة إتجاه عجز الحساب الجاري، وهذا ما يسمى بعجز التوأم وتفسير ذلك أن توسع جز الموازنة يأتي نتيجة لزيادة الانفاق (The Twin Deficit) الحكوي، وبارتفاع الإنغاق الحكوي سينخفض مستوى الإدخار الحكوي والقومي ما
حيث نلاحظ في المعادلة (4)، أن رصيد الميزان التجاري يساوي بمحوع صافي الإدخار الخاص ورصيد الموازنة العامة أي أن عجز الموارد الخارجية يساوي مجموع عزي الإدخار الخاص والموازنة، وفي ظل الإفتراض أن رصيد الإستثار والإدخار الخاص ثابت، العجز في الموازنة سوف يسبب العجز في الحساب الجاري والذي يكون الأساس المنطتي وراء فرضية العجز المزدوج وفق التحليل الكينزي. وللإنتقال من العلاقة بين يجزي الموازنة العامة والميزان التجاري إلى العلاقة بين عجز الموازنة ويجز الحساب الجاري، نضيف التعديلات التالية : 1. يستبدل الدخل المحلي (y) الذي يمثل الناتج المحلي الاجالي (GDP) بالنانج الإجالي القومي (GNP) والذي نرمز له (Y)، ومن الملاحظ أن الإختلاف بين

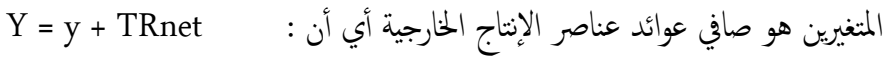
when $\quad$ TRnet $=$ TRin - TRout حيث (TRin) عوائد عناصر الإنتاج المدفوعة من الخارج و

$$
\text { عوائد الإنتاج المدفوعة إلى الخارج. (TRout) }
$$

2. تستبدل الصادرات من السلع والخدمات (EX) بالصادرات من السلع والمدمات X = EX + TRin : وعوائد عناصر الانتاج المدفوعة من العالم الخاري (X)، أي أن 3. تستبدل الواردات من السلع والخدمات (IM) بالواردات من السلع والخدمات M = EM + وعوائد عناصر الإنتاج المدفوعة إلى العالم الخارجي (M)، أي أن و وبذلك يككن إستبدال رصيد الميزان التجاري (TDout الجاري (CAD). وبذلك يككن التوصل إلى العلاقة بين الموازنة العامة والحساب الجاري من خلال العلاقات المتسلسلة التالية : $\mathrm{y}=\mathrm{C}+\mathrm{S}+\mathrm{T}$ $\mathrm{Y}=\mathrm{y}+\mathrm{TRnet} \quad$ So TRnet $=$ TRin - TRout $\mathrm{Y}=\mathrm{C}+\mathrm{S}+\mathrm{T}+\mathrm{TRnet}$

$$
y=C+I+G+E X-I M
$$

$$
Y=C+I+G+(E X+T R i n)-(I M+\text { TRout })
$$

$$
\mathrm{Y}=\mathrm{C}+\mathrm{I}+\mathrm{G}+\mathrm{X}-\mathrm{M}
$$

C + S + T + TRnet = C + I + G + X - M وبحذف الإستهلاك من الطرفين نخصل 
لا يتعدى كنها تأجيلاً لدفع الضرائب التي خفضت حاليا ليعاد دفعها في وقت لاحق، وبالتالي فإن حجم الإدخار المحلي لن يتغير نتيجة الإخفاض الأولي للضريبة الذي سيعوضه الإدخار الخاص. وبذلك يتضح من النكافؤ الريكاردي عدم وجود علاقة بين Yanik, ( بزز الموازنة الناجم عن الإخغاض الأولي في الضرائب ويجز الحساب الجاري 2006,1-2). وهناك تفسيرات اخرى لالية ترافق عجز الموازنة لعجز الحساب الجاري يكن استعراضها فيها يلي : 1. يرى بعض الاقتصادين ان يجز الموازنة ينجم من زيادة الانفاق الحكوي. وبما ان الانفاق الحكوي من عناصر الطلب الفعال، فإن زيادة الإنفاق الحكوي سوف تعمل على زيادة مستوى الدخل عبر آلية مضاعف الإنفاق الحكوي. وبارتفاع مستوى الدخل، يزداد مستوى الواردات، ومن ثم يتسع جز التجارة الخارجية و جز الحساب

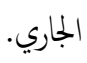
2. إن ارتباط يجز الحساب الجاري بعجز الموازنة ما هو إلا نتيجة للمتطابقة الكينزية التوازنية،

$$
\text { فني وضع التوازن، يكون : (S - I ) = (G -T) + (X -M) }
$$
ونتيجة لانخفاض الادخار القوي (بسبب تخفيض الضرائب او زيادة الانفاق الحكوي) عن احتياجات الاستثڤار، يختل شرط التوازن (S=I))، مما سيؤدي الى تكوين جزز الموازنة اولاثم نشوء جزز الحساب الجاري.

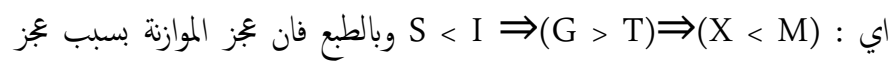
الادخار المحلي عن تمويل الاستثار الحملي، بالامكان سداده عن طريق زيادة صافي الاستثمار الاجنبي المباشر، الامر الذي سيؤدي الى زيادة مديونية الاقتصاد الوطني

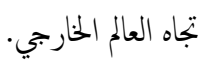
3. تتمثل زيادة الإنفاق الحكوي أو انخفاض إيراداته من الضرائب بعجز في موازنة الدولة، وهذا العجز في الموازنة يدل على انخفاض الادخارالحكوي، باعتبار أن الادخار المحلي مساوي لمجموع الادخار الحكوي والخاص. ويرى البعض أن العجز في موازنة الدولة سيترافق مع فائض في حساب رصيد رأس المال بدلا من العجز في ميزان الحساب الجاري. وينتج هذا الفائض من زيادة تدفق المدخرات الاجنبية بسبب ارتفاع أسعار الفائدة المحلية، المى الاقتصاد الوطني وذلك لاعادة التوازن بين الادخارر والاستثمار، مما سيؤدي المى ظهور فائض بحساب رأس المال، ذلك ان حساب رأس
يؤدي إلى زيادة سعر الفائدة (وفي ظل نظام سعر الصرف المرنة) سيزداد الطلب الأجنبي على العملة المحلية مما يؤدي إلى إرتفاع سعر صرف العملة المحلية مقابل العملات الأجنية، وبارتفاع سعر صرف العملة المحلية تكون الواردات أقل كلفة للمواطنين فتزداد الإستيرادات وتكون الصادرات أكثر كلفة وأقل جذباً للأجانب فتنخفض الصادرات وبالتالي يتكون عجز الميزان التجاري. وبما أن الميزان التجاري هو المحدد الرئسي في تغيرات رصيد الحساب الجاري وعليه يزداد يجز الحساب الجاري. وبذلك يؤدي يجز الموازنة إلى عزز الحساب الجاري ويترافق معه، ويعاني الإقتصاد من توأمة العجزين. وبالرغز من صحة التحليل نظرياً حول العلاقة المباشرة بين عجز الحساب الجاري وعزز الموازنة العامة إلا أنه ينعرض إلى بعض الشكوك حول مدى تطابقها مع الواقع، فقد وضحت بعض الدراسات الإقتصادية بعدم وجود علاقة نظامية بين العجزين، فثنلاً في النوويج، يترافق فائض كير في الموازنة مع عجز كبير في الحساب الجاري. وأيضاً في الولايات المتحدة ترافق جز في الحساب الجاري في الستينات مع فائض الموازنة الفدرالية (الكسواني، 2001، 7). وبذلك طرح المنهج النيوكلاسيكي تحليلاً خختلفاً للموضوع جاء به Barro (1989 والذي بناه لهديه من أفكار سلفه العالم الكبير (ريكاردو) وهذا الطرح سمي بالمكافٔع الريكاردي نسبة إلى (ريكاردو) والذي يرى بعدم وجود علاقة بين حالات العجز في الموازنة والعجز التجاري، وهو يرفض مفهوم العجز التوأم على إفتراض عدم وجود فرق بين الإقتراض وفرض الضرائب على تمويل الديون، وتقول الفرضية أن الأفراد لا يزيدوا إستهلاكهم إستجابةً لخفض الضرائب نتيجة توقعاتهم العقلانية، وأنه سيتم تعويض خفض الضرائب الحالية بزيادتها في المستقبل (-Hany et al. , 2010, 8). 2.3 النكافو الريكاردي (The Ricardian Equivalence) يرى النكفؤ الريكاردي بعدم وجود علاقة بين عجز الموازنة العامة ويجز الحساب الجاري، وتفسير ذلك أن إنساع عجز الموازنة العامة نتيجة لتقليص الضرائب Tax) ذو أثز مؤقت لابد أن تتلاشى أثاره برجوع الضرائب إلى مستوياتها الأصلية. ويبين النكفؤ الريكاردي أن إنخفاض المدخرات الحكومية سيترافق مع زيادة مكافئة في المدخرات الخاصة ذلك أن الأفراد يتوقعون أنه مع إنخفاض الإدخار العام أو الحكوي سوف يزيد من أعبائهم الضريبية في المستقبل، وبالتالي فع عجز الموازنة يتوقع الأفراد زيادة مستوى الضريبة في المستقبل وعليهم التحسب من الان بوضع بعض المدخرات لمواجهة تلك الضرائب المتوقعة بالزيادة. أي أن هبوط الضرائب ليس إلا عملية مؤقتة 
2.4.1 2 دراسة (Khalid \& Guan, 1999) بعنوان (العلاقة السببية بين عجز

الموازنة والحساب الجاري : المقارنات بين الدول)

توبحت الدراسة إلى تحليل التكامل المشترك لتحديد العلاقة السبية بين عزز الحساب الجاري والموازنة بإستخدام عينة السلاسل الزمنية السنوية لحمس بلدان متقدمة النمو وخمس بلدان نامية، وأوحت نتائُ التكمل المشترك أن التوافق بين العجزين في المدى الطويل من المربح أن يحدث في البلدان النامية أكثر من البلدان المتقدمة، ووجدت أن نتاجُج إختبار السبية تدعز وجود العلاقة السبية المزدوجة الإتجاه بين يجز الحساب الجاري والموازنة في الدول النامية، وتشير الأدلة إلى أن العجز في الحساب الجاري يسبب عجزاً في الميزانية لإندونيسيا وباكستان، في حين أن العكس صحيح بالنسبة لمصر والمكسيك. والبيانات لا تدع أي علاقة سبية في المملكة المتحدة وأستراليا، وتدع فقط بعض الأدلة الضعيفة للعلاقة السببية ثنائية الإتجاه لكل من كندا والهند. 2.4.2 2 دراسة (Vamvoukas, 1999) بعنوان (ظاهرة العجز التوأم : حالة يونان) وضحت الدراسة حالة العجز التوأم للإقتصاد اليوناني، وإستخدم بيانات سنوية للفترة (1993-1948) لحالة جز الميزان التجاري والموازنة، وإستخدم نموذج تصحيح الخطأ، وتحليل النكامل المشترك، وسبية غرانجر ، ووجدت أن العلاقة السببية هي من عجز الموازنة إلى العجز التجاري وهو ما يتفق مع الإقتراح الكيزي في المدى الطويل والقصير.

2.4.3 دراسة (Piersanti, 2000) بعنوان (ديناميكية الحساب الجاري والثوقعات

المستقبلية لعجزالموازنة : بعض الادلة الدولية)

وضحت الدراسة نموذجاً متوازناً للتوازن العام لإظهار العلاقة النظرية بين العجز الملالي والحساب الجاري في بلدان منظمة التعاون والتنمية الإقتصادية. ووجدت الإختبارات التجريبية بإستخدام معادلة الإقتصاد القياسي المبنية على نوذج التوقعات المستقبلية، التأييد بقوة وجحة النظر القائلة بأن العجز في الحساب الجاري مرتبط بعجز الميزانية المتوقعة مستقبلاً خلال الفترة (1970-1997).

2.4.4 دراسة (الكسواني، 2001) بعنوان (العلاقة بين عزي الموازنة والحساب الجاري في المملكة العربية السعودية خلال الفترة 1970-1999) ناقشت الدراسة الأساس النظري لنظرية العجز المزدوج من حيث المتزح الكينزي الذي يؤكد أن عجز الموازنة يؤدي إلى جزز الحساب الجاري وفرضية التكفؤ الريكاردي القائلة بعدم وجود العلاقة بين العجزين، وخلصت الدراسة إلى وجود علاقة طويلة
المال يعاكس رصيد الحساب الجاري (الكسواني، 2001، 9-10).

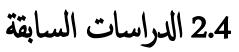

ظهرت في الآونة الأخيرة وبحات نظر متباينة في هذا الشأن وهذا محم لصناع السياسة Jayaraman \& ( في فهم العلاقة بين نظرية جزز الموازنة ويزز الحساب الجاري Choong, 2007 فأما وبجة النظر الأولى فتنطلق من أنه في في ظل نظام صرف رك مرن وظروف مثالية لإنتقال رؤوس الأموال بين الدولة وبقية العالم، يمارس عجز الموازنة ضغوطاً لصعود معدل الفائدة الذي يؤدي إلى تدفق رؤوس الأموال وبالتالي إرتفاع قيمة سعر الصرف (Fleming \& Mundell, 1962) ويتكيف سعر الصرف ويستعيد التوازن الخارجي. ومن ناحية أخرى، في ظل نظام سعر صرف ثابت، ورقابة على سعر الصرف، لا يتم إستعادة التوازن الخارجي التلقائي، وإحداث جزز في الحساب الجاري يمول عادةً من الإحتياطيات الدولية، مشيراً إلى تدخل الحكومة، ويؤدي عجز الموازنة المستمر إلى إستمرارية العجز في الحساب الجاري. وقد أظهرت التجارب أن تمويل عجز الحساب الجاري يتم من خلال تدفقات المحافظ المالية والإستثار المباشر الذي يضيف موارد حقيقية. ومن بجة أخرى يوجد شكلين للمويل : سحب الإحتياطيات الدولية والإقتراض من الخارج وها يجعلان الحساب الجاري غير مستقراً. وأما وبحة النظر الثانية، فقد تأسست على المنهج النقدي لميزان المدفوعات لدولة صغيرة في ظل نظام سعر الصرف الثابت، وإستناداً إلى نظرية الإستيعاب الكينزية، والمنهج النقدي فأي زيادة في يجز الموازنة من شأنه أن يؤدي إلى زيادة في الطلب الكلي، وتنتقل إلى الطلب على السلع والخدمات من الخارج وزيادة المستوردات، وبالتالي يفاقم مستوى الإستيرادات عجز الحساب الجاري. ويعمد رأي ثالث إلى فرضية النكفؤ الريكاردي، حيث يشير هذا الرأي إلى عدم وجود علاقة بين جزز الموازنة ويجز الحساب الجاري لأن الإنتقال بين الضرائب ويجز الموازنة لا يؤثر على أسعار الفائدة الحقيقية، ومستوى الإستثمار ، أو العجز في الحساب الجاري وقد تم إختبار العلاقة بين جزز الموازنة ويجز الحساب الجاري، أو ما يسمى بفرضية العجز التوأم لدول متقدمة، خصوصاً الولايات المتحدة الأمريكية، وأغلها وجدت صلة وإتجاه واحد من جزز الموازنة إلى عجز الحساب الجاري. ولم تكن الآراء متوافقة حول طبيعة العلاقة بين عجز الحساب الجاري والعجز في الموازنة (السواعي والعزام، 2015، 9). 
2.4.8 دراسة (الثيب، 2017) بعنوان (الأرض الفلسطينية المحتلة : حالة عزز

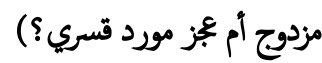

وجدت الدراسة أن هناك تناوت كبير بين الدخل المحلي والناتج المحلي للإقتصاد الفلسطيني خلال الفتزة (1968-2014) وإنغكس ذلك إلى حدوث عجز هائل في الموارد وبالنالي إلى إختلالات تتمثل في غجز تجاري ويجز في المدخرات (الإستثار الوطني يتجاوز المدخرات الوطنية) وجزز في الموازنة، وكانت النتائج التجريبة أن عجز الميزان التجاري هو الاكبر بين العجوزات الثلاث، وأنه لم ينشأ نتيجة تغيرات عجز الموازنة كما مفترض في إطار نظرية العجز المزدوج، إضافةً إلى إختبار الغرانجر السببية

قد فند صحة ذلك.

3. تحليل تطورجز الموازنة والحساب الجاري في العراق للمدة (1988-2016)

3.1

تعكس موازنة الدولة فائضاً إذا زادت إيرادات الدولة عن نفقاتها، ويجزاً إذا زادت نقات الدولة عن إيراداتها. ويمثل الفائض عادةً برصيد موجب، والعجز برصيد سالب، ويكن توضيح تطورجز او فائض الموازنة العامة من خلال بيانات الجدول (1) حيث كانت الموازنة العامة للإقتصاد العراقي يعاني من يجز دائم خلال فترة الثانينات وذلك بسب ظروف الحرب العراقية الإيرانية مما أثر ذلك على الحساب الجاري بشكل سلبي، حيث نلاحظ أن الموازنة العامة عكست حالة الفائض في عام (1988) وذلك كر بسب توقف الحرب وإنخفاض النفقات العسكرية، إلا أنه إرتغ عزز الموازنة بشكل كبير في عام (1991) بنسبة (6\%) مقارنة بعام (1989) وذلك بسبب فرض الحصار والعقوبات الدولية وإنخفاض الواردات النفية، ونلاحظ أيضاً إخفاض جزز الموازنة في سنة (1997) مقارنة بسنة (1996) من (311. 5) مليون دولار الى (268. 7) مليون دولار، وأيضا انخضض بنسبة (66\%) في عام (1997) مقارنةً بعام (1993) وذلك بموجب العمل على مذكرة الثفاهم (النفط مقابل الغذاء)، وقد حققت الموازنة العامة فائضاً في عام (2004) بتمة (598. 2) مليون دولار بسبب رفع العقوبات الدولية إضافةً إلى إرتفاع أسعار النفط العالمية التي إستمرت بالزيادة إلى أن وصلت إلى (88. 8) دولار للبرميل الواحد في عام (2008) حيث حقت الموازنة العامة فائضاً كيراً بلغ (17330. 67) مليون دولار. وكذلك حققت الموازنة العامة أعلى فائض خلال مدة الدراسة في عام (2011) بعقدار (25125. 18) مليون دولار. ويرجع ذلك
وقصيرة الأمد بين العجزين، إضافةً إلى وجود علاقة سبية مزدوجة الإتجاه بين العجزين.

\section{4 .5}

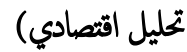

في هذه الدراسة تم إستخدام نموذج الإنحار الذاتي للفجوات الزمنية الموزعة (Pesaran et al. , 2001) لتقييم الديناميكات (ARDL) على المدى الطويل بين العجز المزدوج في سريلانكا للفترة (1970-2003). و يدع التحليل التطبيقي في هذه الدراسة وبهة النظر الكينزية بأن هناك علاقة طوياة الأمد بين إختلالات الحساب الجاري ويجز الميزانية. كما تظهر النتأُ التجريبة أن التجاه السببية يمتد من يجز الميزانية إلى عزز الحساب الجاري. وبالتالي، يكنن لأي تدابير سياسية للحد من العجز في الميزانية في سريلانكا يجب أن تساعد في الحد من الاختلالات الحالية في ميزان الحساب الجاري.

\subsection{6 دراسة (Kim \& Kim, 2006) بعنوان (هل كوريا لدها العجز التوأم؟)}

Toda \& Yamamoto, ) اشارت الدراسة إلى إختبارWald المعدل الذي إقترحه 1995) لبحث ما إذا كانت زيادة عجز الموازنة تؤدي إلى زيادة العجز في الحساب الجاري في كوريا. وأثشارت النتائُ التطبيقية إلى وجود علاقة سبية أحادية الإتجاه تمتد من عزز الحساب الجاري إلى عجز الموازنة في كوريا. 2.4.7 2 دراسة (Magazzino, 2012) بعنوان (ظاهرة العجز التوأم : ايطاليا حالة

أشارت الدراسة إلى التحليل القياسي للسلسلة الزمنية بين جز الحساب الجاري والموازنة في إيطاليا للفتزة (1970-2010). ولقد وجدت أن الميزان التجاري سبب عجز الموازنة، ببنا علاقة النكامل المشترك في الأجل الطويل ليس موجوداً بين هذه المتغيرات. ونتائج هذه الدراسة أشارت إلى أن تصحيح الإختلالات الخارجية يككن الحكومة الإيطالية من تحسين سياق المالية العامة، الذي يمثل في الواقع النقطة الحاسمة للبلد. وبالتالي تجديد التوازن التجاري يجب أن يعزز الإجراءات المالية الجديدة المفروضة من قبل صانعوا السياسة الإيطالية. 
أسعار النفط العلمية بنسبة (40\%) مقارنة بعام (2008) والذي حقق في نفس العام اعلى فائض خلال مدة الدراسة بلغ (28440. 9) مليون دولار، وكان من أهم الأسباب الرئسية لناك الفوائض هو زيادة صادرات النفط وأسعاره العالمية، حيث بلغ سعر برميل النفط حوالي (88. 8) دولار مما بلغت الصادرات النفطية بحدود (58) مليار دولار أي بنسبة (96\%) من الايرادات الكلية للموازنة، بينا في عام (2015) أصبح الحساب الجاري في حالة جز والذي تزامن مع الإتثاع الكبير في ججز الموازنة الذي بلغ (8649. 7607) مليون دولار، بسبب تراجع أسعار النفط التي وصلت إلى أقل من (35) دولار للبرميل الواحد، وزيادة الإنفاق العسكري على محاربة التنظيم الإرهابي (داعش) في شهال البلاد وغرها. وحقق الحساب الجاري فائضاً في عام (2016) بسب تراجع عزز صافي الخدمات من (11459. 2) مليون دولار في عام (2015) إلى (7593. 8) مليون دولار في (2016) نضف إلى ذلك زيادة فائض حساب الدخل الثانوي من (543. 4) مليون دولار إلى (1005. 5) مليون دولار في المدة نفها. ويكن ملاحظة أهمية الإيرادات النفطية كصدر رئيسي لإيرادات الدولة حيث بلغ معدل متوسط نسبة الإيرادات النفطية إلى إجلالي إيرادات الدولة إلى حوالي (90\%) خلال فتزة الدراسة كما مبين في الشكل رقٌ (2). في حين تراوحت نسبة الصادرات النفية إلى إجالي الصادرات ما بين (92\%-96\%) خلال نفس المدة، لذلك يتبين أهمية الإيرادات النفطية في كل من رصيدي الموازنة العامة والحساب الجاري والعلاقة الوثيقة ما بين العجزين خلال فترة الدراسة، حيث فائض الحساب الجاري ترافق مع فتزة إرتفاع أسعار النفط (2005-2014)، وحقق العجوزات الكبيرة خلال فتزة إنغاض أسعار النفط (1988-2004) و(2015-2016) كما موضح في الجدول والشكل رقز (1)، لذلك يبدو أن العائدات النفطية هي المكون الأساسي لرصيد الحساب الجاري والمصدر الرئيسي لإيرادات موازنة الدولة في الإقتصاد العراقي.
إلى الإرتفاع في أسعار النفط العالمية حيث بلغ (103) دولار للبرميل الواحد ومع إستمرار إرتفاع أسعار النفط إلى أن وصل (106) دولار في عام (2012)، لكن في المقابل إنخضض فائض الموازنة بنسبة (3. 2\%) عن العام السابق والذي تزامن مع أعلى فائض حققه الحساب الجاري حيث بلغ (29542) مليون دولار في نفس العام، مما إنخضت نسبة الفائض في الموازنة لعام (2012) إلى الناتج المحلي الإجلالي بحدود (11. \%) مقارنة بنسبة (14. 2\%) لعام (2011) نتيجة لزيادة النفقات العامة بشقيه الإنفاق الجاري والإستثماري بنسبة (14. 3\%) و (16. \%) على التوالي في حين حققت الموازنة جززاً في عام (2013) بمقدار (4729. 4) مليون دولار لإنخفاض أسعار النفط بالإضافة إلى زيادة النفقات الجارية. وإستمر جزز الموازنة في عام (2014) بعقدار (66. 3) مليون دولار بسبب الهبوط السريع لأسعار النفط حيث وصلت في نهاية عام (2014) إلى (53) دولار للبرميل. واستمرت زيادة العجز في الموازنة العامة حتى بلغ في أعلى مستوى خلال مدة الدراسة في عامي (2015-2016) بتمة (8649. 7607) و (10637. 11) مليون دولار على التوالي، نتيجة الإنخاض الكبير في أسعار النفط التي وصلت إلى أقل من (35) دولار للبرميل الواحد. إضافةً إلى سوء الأوضاع الأمنية وزيادة الإنفاق العسكري ضد الإرهاب، وكذلك الزيادة في إنتاج النفط الصخري للولايات المتحدة وتراجع الطلب في الصين بسبب تباطؤ إقتصادها.

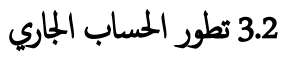
يعرف الحساب الجاري بأنه الفرق بين الصادرات من السلع والخدمات وعوائد عناصر الإنتاج المحولة من العالم الخارجي (ونسميها إختصاراً الصادرات)، والواردات من السلع والخدمات وعوائد عناصر الإنتاج المولة إلى العالم الخارجي، (ونسميها إختصارا الواردات)، ويكن ملاحظة تطور رصيد الحساب الجاري من خلال الجدول (1)، حيث حقق الحساب الجاري جزاً بلغ (2872. 1) مليون دولار في عام (1989) وإستمر العجز بالزيادة إلى أن وصل (7076. 1) و (10129. 7) مليون دولار في عام (1992) و (1997) على التوالي بسبب إنخفاض صادرات النفط نتيجة الحصار الإقتصادي. وكذلك في عام (2003) الحساب الجاري كان في حالة العجز بغض النظر عن إنخفاضه مقارنةً بعام (2002) بمقار (934. 5) مليون دولار، ويرجع أسباب إرتفاع العجز إلى جزز الميزان التجاري وميزان الخدمات وبالأخص صادرات النفط (بسبب عمليات التخريب لأنابيب تصدير النفط). وفي المقابل حقق الحساب الجاري فوائض كيرة خلال الفترة (2005-2014) ما عدا سنة (2009) بسبب إنغاض 
بين العجزين في إقتصادات الدول المتقدمة أو الغير نقية (سالم، 2012، 307). حيث وضح الجدول (1) أعلاه حالات العجز والفائض في كل من الموازنة العامة والحساب الجاري للفتزة (1988-2016)، لذلك تكون طبيعة العلاقة بين العجزين في

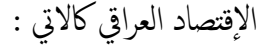

1. العلاقة بين عجز الموازنة وجزز الحساب الجاري في الإقتصاد العراقي لا ينجج عن تخفيض الضرائب على الدخل وإنما ينجم عن إرتفاع الإنفاق الحكوي خاصةً النفقات الجارية حيث بلغ متوسط نسبة الإنفاق الجاري إلى النفقات الكلية حوالي (78\%) خلال السنوات (2003-2016)، أما إيرادات الحكومة فتكون العائدات النفطية مصدرها الأساسي وكما هو معروف أن أسعار النفط يتحدد وفق الطلب الخارجي وبذلك تعتبر عائدات النفط متغيراً خارجياً لا يكن التحكي به، مما يدل طبيعة العلاقة بين يجز الموازنة وجزز الحساب الجاري ومكوناتها أن هناك إرتباط قوي بين الصادرات تقدر ب (X) والايرادات (T) و (T) حيث أن معامل الإرتباط الخطي بين (T) (98\%) في العراق. مما ينجم عن ذلك أن السياسة المالية التوسعية أدت إلى زيادة الإنفاق (G) وبالثالي زيادة جزز الموازنة (T > ما مؤدي إلى إرتفاع الدخل المحلي الغير النفطي وبالتالي إلى إرتفاع الواردات ولعدم مرونة الجهاز الإنتاجي يكون الإستيعاب أو الإمتصاص المحلي الذي يتكون من الإستهلاك (C)، الإستثمار الخاص (I) الإنفاق الحكوي (I) والصادرات (I) الناتج المحلي وعليه ينتج حالة العجز في الميزان التجاري، خاصة أن اغلب صادرات العراق يتكون من النفط الخام اضافة المى بعض المنتجات الزراعية مما تجعل هذه السلع معرضة للصدمات الخارجية ما ينتج عنها أثار سلبية على ميزان المدفوعات نتيجة إختلال الهيكل الإنتاجي للعراق والذي ينجم عن سيادة الإنتاج الأولي (شاني و فاضل، 2001). وبما أن الميزان التجاري المكون الرئيسي للحساب الجاري وبالتالي يزداد عزز الحساب الجاري، والذي نتج عن جزز الموازنة بسبب زيادة نقات الدولة. لذلك نجد أن مبدأ النكفؤ الريكاردي القائم على تخفيض الضرائب لا يكون فعالاً في الإقتصاد العراقي لعدم وجود دور فعال للضرائب كتغير من متغيرات السياسة المالية. 2. سياسة الإقتصاد العراقي خاصةً بعد عام (2003) سياسة مالية توسعية نتيجة زيادة الأجور والخدمات وتدهور الوضع الإقتصادي (Alrubaie, 2010, 16) والأمني، بالمقابل يوابتها سياسة نقدية متشددة من خلال زيادة اسعار الفائدة المحلية
الجدول (1) : تطور العلاقة ما بين يجز الموازنة ويجز الحساب الجاري خلال فترة الدراسة (1988-2016) مليون USD

\begin{tabular}{|c|c|c|}
\hline $\begin{array}{l}\text { السنوات } \\
\text { Years }\end{array}$ & $\begin{array}{c}\text { الفائض أو العجز في الموازنة } \\
\text { (BD) }\end{array}$ & الحساب الم الجاري العزي في \\
\hline 1988 & 3465.85 & -3717.5 \\
\hline 1989 & -2526 & -2872.1 \\
\hline 1990 & -2844 & -2418.2 \\
\hline 1991 & -6634.5 & -4197.1 \\
\hline 1992 & -1325.5238 & -7076.2 \\
\hline 1993 & -810.22973 & -8451.2 \\
\hline 1994 & -379.43886 & -9127.9 \\
\hline 1995 & -348.74432 & -10547.1 \\
\hline 1996 & -311.56325 & -10046 \\
\hline 1997 & -268.70496 & -10129.7 \\
\hline 1998 & -246.95741 & -12045.1 \\
\hline 1999 & -4875.5005 & -14527.9 \\
\hline 2000 & -189.46425 & -8169.1 \\
\hline 2001 & -409.78797 & -15310.2 \\
\hline 2002 & 35. 5574859 & -15762.4 \\
\hline 2003 & 84. 606405 & -934.5 \\
\hline 2004 & 598. 243634 & -2404.6 \\
\hline 2005 & 9597.63247 & 1694.1 \\
\hline 2006 & 6953. 68271 & 7095.6 \\
\hline 2007 & 12698. 3842 & 20062.7 \\
\hline 2008 & 17330. 6791 & 28440. 9 \\
\hline 2009 & 2235.47208 & -1142.5 \\
\hline 2010 & 37. 1180438 & 6477.4 \\
\hline 2011 & 25125.189 & 26128.8 \\
\hline 2012 & 11904. 013 & 29542 \\
\hline 2013 & -4729.4097 & 22590.3 \\
\hline 2014 & -6630.414 & 24427. 9 \\
\hline 2015 & -8649.7607 & -1913.1 \\
\hline 2016 & -10637.115 & 3554.7 \\
\hline
\end{tabular}

المصدر : إعداد الباحثان بالإعتاد على التقارير السنوية للبنك المركزي العراقي، المديرية العامة للأحصاء والأبحاث

\section{3 تحليل العلاقة بين عزز الحساب الجاري وعزز الموازنة في الإقتصاد العراقي}

لاشك أن إقتصاد العراق يتصف بأنه من الإقتصادات النفطية الذي ينكون من سلات تختلف فيه طبيعة العلاقة بين جزز الموازنة وجز الحساب الجاري عن طبيعة العلاقة 
خلال سبع سنوات بنسبة (10\%) (البنك الدولي، 2015). حيث يوضح الجدول رقز (2) مدى تذبذب اسعار النفط العالمية وأثره على ايرادات الاقتصاد العراقي. الجدول (2) : تذبذب متوسط أسعار النفط العالمية

خلال فترة الدراسة (1988-2016)

\begin{tabular}{|c|c|c|}
\hline السنوات & متوسط اسعار النفط & نسبة التغيير \% \\
\hline 1988 & 17 & \\
\hline 1989 & 5.17 & 2.9 \\
\hline 1990 & 23 & 31.4 \\
\hline 1991 & 24 & 4.3 \\
\hline 1992 & 6.23 & -1.6 \\
\hline 1993 & 4.24 & 3.38 \\
\hline 1994 & 25 & 2. 45 \\
\hline 1995 & 7.23 & -5.2 \\
\hline 1996 & 5.24 & 3.37 \\
\hline 1997 & 25 & 2.04 \\
\hline 1998 & 11 & -56 \\
\hline 1999 & 16 & 45.45 \\
\hline 2000 & 22 & 37.5 \\
\hline 2001 & 17 & -22.72 \\
\hline 2002 & 25 & 47. 05 \\
\hline 2003 & 40 & 60 \\
\hline 2004 & 50 & 25 \\
\hline 2005 & 53.5 & 7 \\
\hline 2006 & 63 & 17. 75 \\
\hline 2007 & 62.6 & -0.63 \\
\hline 2008 & 88.8 & 41.85 \\
\hline 2009 & 58.9 & -33.67 \\
\hline 2010 & 75.6 & 28.35 \\
\hline 2011 & 103 & 36.24 \\
\hline 2012 & 106.3 & 3.20 \\
\hline 2013 & 103 & -3.10 \\
\hline 2014 & 96.8 & -6.01 \\
\hline 2015 & 35 & -63.84 \\
\hline 2016 & 45 & 28.57 \\
\hline
\end{tabular}

فهذه التذبذبات الغير متوقعة في أسعار النفط العالمية تؤثر سلباً على الموازنة ومن ثم على الحساب الجاري، لذلك يفضل تنوع مصادر إيرادات الإقتصاد العراقي من خلال

وتثثيت سعر الصرف المحلي مقابل الدولار عن طريق المزاد العلني لبيع وشراء العملة (للسيطرة على التضخم) ما أدى الى استقرار سعر الصرف المحلي، لكن في المقابل ارتفاع اسعار الفائدة وتقليص الاحتياط النقدي المركزي أدى الى تقليص المشاريع الاستثمرية وبالتالي انخفاض النمو الاقتصادي، مما دل ذلك على عدم فعالية ادوات السياسة النقدية، من معدل الفائدة وغيره في تحفيز وزيادة الاستثار، ماعدا سعر الصرف ودوره في انخفاض مستويات التضخم، في حين أن إنخاض التضخم لا يكون بالضرورة مؤشراً إيهابياً، خاصة اذا كانت السبب ظرف خارجي وقاهر ، كما هو الحال الآن في العراق، حيث تقلصت موارد البلد وفرضت سياسات تقشفية من قبل الدولة، وتقاصت المعاشات وفرضت تكاليف ورسوم أخرى على المواطن، وهاجر المواطنون خارج البلد، وعرضوا مساكنهم للبيع أو الإيجار بأبخس الأثمان، فإنخضت أسعار العقارات، وإنخضت ألإيجارات، اضافة الى الجو التشاؤي للاقتصاد اي بمعنى ليس هنالك استثمار حقيقي وزيادة انتاجية يعطي الناس دفعات لزيادة الطلب والثناؤل الاقتصادي مما ينج عن ذلك حالة الانكماش والكساد الاقتصادي وهذا ما يدل عليه في السنوات الأربعة الأخيرة خلال فترة الدراسة (2013-2016) حيث كان معدل رصيد الحساب الجاري إلى الناتج الإجالي المحلي فائضاً بجوالي (5. 3\%) وذلك لإنخفاض الطلب الكلي وبالتالي إخفاض الإستيرادات بغض النظر عن معدل عجز الموازنة إلى الناتج المحلي بحوالي (4\%) في نفس الفترة بسبب زيادة الإنفاق العسكري. 3. نلاحظ أنه في الإقتصاد العراقي العجز في الميزان التجاري له أثر سلبي كير على إيرادات الموازنة العامة للدولة ذلك عندما يكون هناك ناتج محلي ضعيف (عدم مرونة الجهاز الأنتاجي) لأستيعاب الطلب المحلي النابج عن زيادة النفقات فيؤدي الى زيادة الطلب المحلي على السلع الأجنبية ما يتحول الاموال المى الخارج بدلا من استخدامحا في المشاريع المحلية المنتجة مما ينجم عن ذلك عدم وجود مصادر اخرى لزيادة ايرادات الدولة. . وهذا يعني أن إختلال الهيكل الإنتاجي للدولة يؤدي إلى تفاقم الأزمة والعجز الملالي في الإقتصاد العراقي. نضف إلى ذلك تذبذبات أسعار النفط العالمية (كون صادرات النفط المصدر الرئيسي لايزادات الموازنة) بنسب عالية خلال فتزة قصيرة ما بين ( تموز-كانون الثاني 2014) إنخفت أسعار النفط بنسبة (55\%) حيث في يوم واحد (28/ تشرين الثاني 2014) بلغت نسبة الهبوط حوالي (10\%) وفي العام التالي (2015) بلغت أسعار النفط في شهر (أب) أعلى نسبة إرتفاع في يوم واحد 
مما يعني ذلك، أنه في حالة زيادة نقات الدولة على السلع الرأسمالية المتتجة وتحفيز الإستثمار في المشاريع بكافة أنواعها لزيادة النمو والتنمية الإقتصادية سوف يكون له ذو أثر إيجابي على ميزان المدفوعات وبالتالي على تحسين وزيادة إيرادات موازنة الدولة، أي أنه خلال فترات الإنكماش الإقتصادي، يكون الناتج الحلي الإجالي عادة دون ما هو منكن ولذلك فإن حدوث زيادة في الإنفاق الحكوي يمولها العجز ويككن أن يؤدي إلى زيادة الناتج المحلي الإجلالي. وفي مثل هذه الحالة لا يعود إفتراض ثبات الناتج المحلي

الإجلالي (على خو ما تشير إليه نظرية العجز المزدوج) إفتراضا صحيحاً (النقيب، 2017، 8). ويوضح الشكل (1) أدناه أن أغلب حالات العجز والفائض في الموازنة العامة قد رافقها حالات العجز والفائض في الحساب الجاري وبالعكس، وكذلك الشكل (2) أيضا يبين حجم الايرادات النفطية الكبيرة مقارنة بالإيرادات الكلية خلال نفس الفترة، مما يؤكد العلاقة والإرتباط القوي بين زيادة أسعار وصادرات النفط وبالتالي إيرادات النفط وإرتفاع فوائض كل من الموازنة العامة والحساب الجاري خلال الفتزة (2004-2014).
زيادة النفقات على السلع الرأسمالية التكنولوجية المنتجة وتشجيع القطاع الخاص لتنفيذ المشاريع الصغيرة والمتوسطة الأجل من جهة وتخفيز الإستثارات الأجنية للقيام بمشاريع بنيوية ضخمة من جهة أخرى ما يؤدي إلى زيادة الناتج المحلي الإجلالي، ثم تخفيض الإستيرادات وبالتالي تقليص العجزين، إضافةً إلى زيادة النمو الإقتصادي لأن النظريات الحديثة المتعلقة بالنمو المحلي الذاتي يؤيد ذلك فثلاً أشار ( Evenson \& (Wistphal, 1995 إلى أنه (ما من بلد من البلدان أقل نمواً قد حقق حتى الآن نمواً إقتصادياً سريعاً من دون إستثار تكنولوجي متواصل) وتؤيد ذلك ايضا التجارب العملية فعلى سبيل المثال، المشروعات الصغيرة والمتوسطة تمثل نحو (90\%) من إجالي الشركات في معظم إقتصاديات العالم، كما تسهم هذه المشروعات بجوالي (46\%) من الناتج المحلي العالمي، كما أنها توفر ما بين (40\% - 80\%) من إجالي فرص العمل، وتساهم بنسبة كيرة في الناتج المحلي للعديد من الدول، فعلي سبيل المثال تساهم المشروعات الصغيرة والمتوسطة بنحو (85\%، 51\%) من إجلالي الناتج المحلي في كل من انجلترا والولايات المتحدة الأمريكية على التوالي (Alasrag, 2010, 5-7).

الشكل (1) : تطور العلاقة ما بين جزز الموازنة ويزز الحساب الجاري خلال فترة الدراسة (1988-2016)

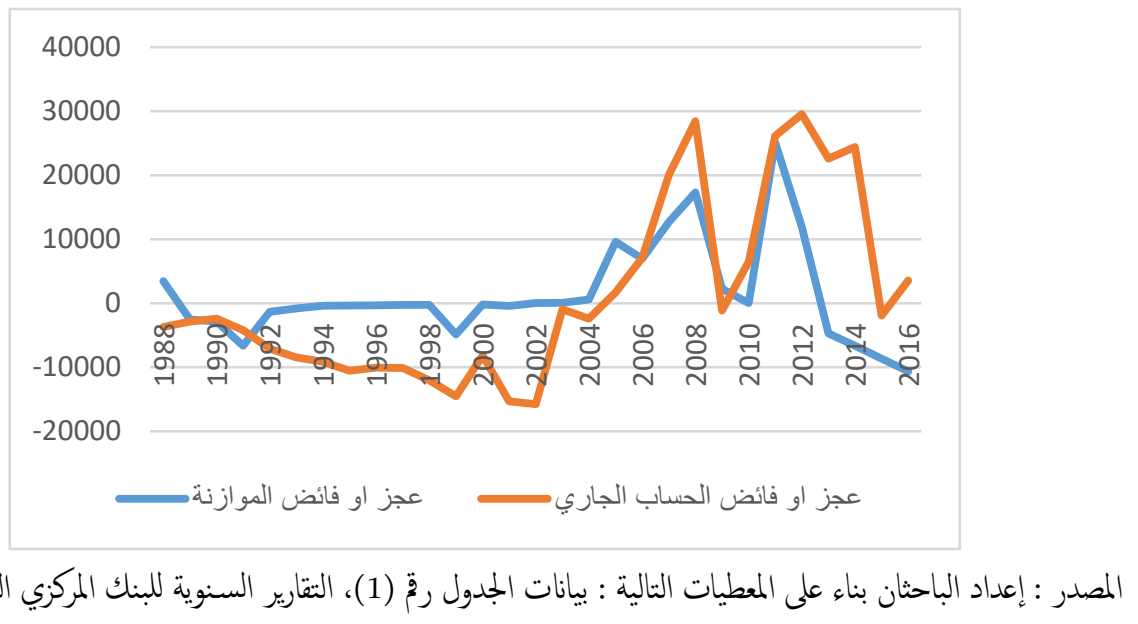


الشكل (2) : ججم الإيرادات النفطية بالنسبة للإيرادات الكلية خلال فترة الدراسة (1988-2016) مليون USD

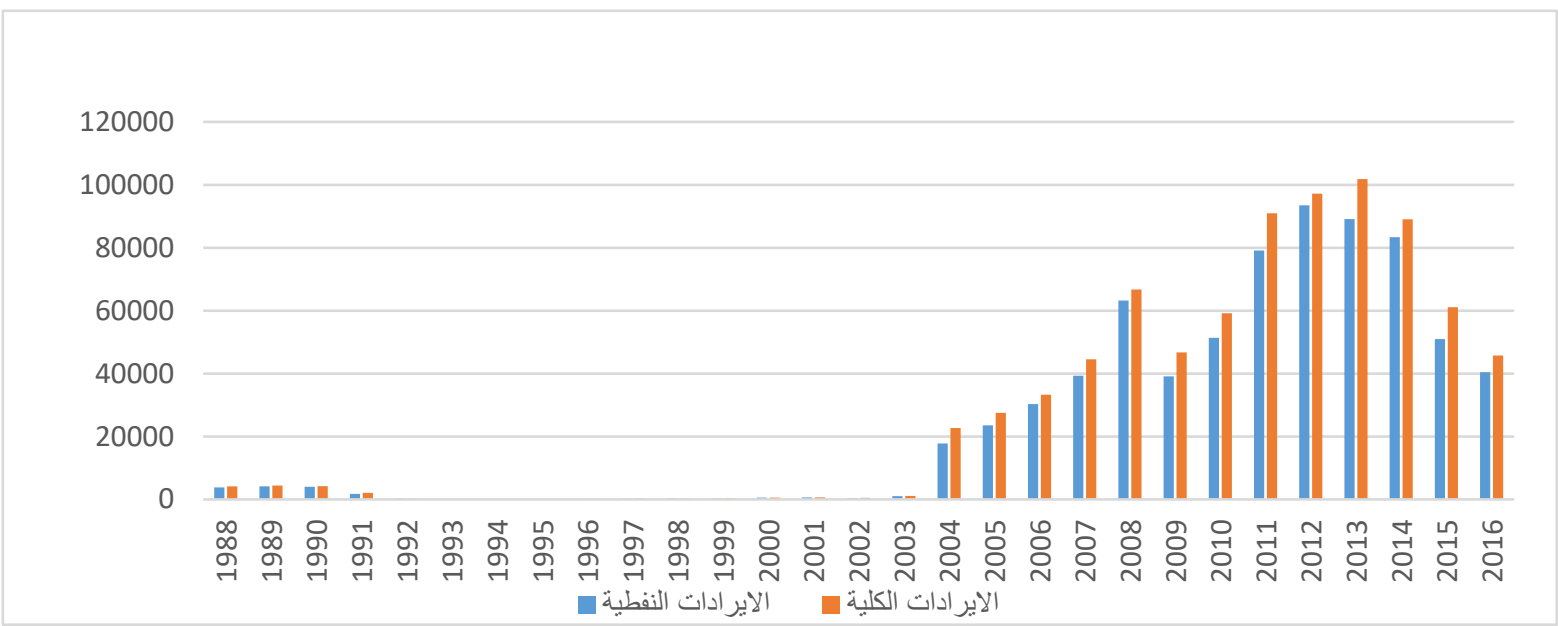

المصدر : إعداد الباحثان بناء على المعطيات التالية : بيانات الجدول رق (1)، التقارير السنوية للبنك المركزي- دائرة الأحصاء

4. من خلال النقاط السابقة يثار السؤل الاتي هل يوجد علاقة سببة مزدوجة بين الجاري. وتجدر الاشارة إلى أن سبب حدوث العجز في الموازنة العامة لا يمكن إرجاعها يجز الموازنة و عزز الحساب الجاري؟ لاشك أن الإقتصاد العراقي هو إقتصاد ريعي إلى سبب وحيد لأها ظاهرة مركبة ومعقدة. ومن أبرز هذه الأسباب منها عدم مواكبة والذي يكون النفط فيه (أكثر من 90\%) هو المصدر الرئيسي لايرادات الدولة، الموارد والإيرادات العامة للنمو الحاصل في النفقات العامة (الشمراني، 2010، 12)، وبالتالي فإن توقع زيادة العائدات النفطية تؤدي إلى إرتفاع النفقات الحكومية (G)، كما أن ججم الانفاق العام وتطوره يعكس مدى تطور حجم الحكومة ودورها في النشاط وبما أن النفقات عنصر من عناصر الطلب مما سيؤدي إلى إرتفاع الدخل الغير النفطي، الإقتصادي، بالإضافة إلى إرتفاع نسبة النفقات الجارية إلى إجالي النفقات العامة وبما أن مرونة الجهاز الإنتاجي ضعيفة سترتع الأسعار وكذلك تؤدي إلى زيادة الطلب وتفشي حالات الفساد الحكوي وحدوث الأزمات الإقتصادية وتزايد الإنفاق العسكري على السلع الأجنبية المستوردة لتلبية أو إمتصاص الطلب الداخلي وبالتالي ستزداد (الخطيب وزهير، 2007، 236). ويككن القول إلى أن المعالجة الموضوعية والرشيدة الواردات (M) وبإرتفاع الواردات سيرتفع العجز في الحساب الجاري، فبسبب زيادة لعجز تتطلب عدم خسارة العراق لدع ودور صندوق النقد الدولي والمؤسسات الإنغاق الحكوي خاصة (النفات الجارية) مما ينتج عن ذلك زيادة جزز الموازنة وبالتالي الدولية والإقتادية الأخرى، والناكيد على إنتاجية النفقة العامة وترشيدها وتأهيلها، إرتفاع في عجز الحساب الجاري أي هناك علاقة طردية من كجز الموازنة بإتجاه عزز بالإضافة إلى التأيد على ضرورة إلتزام وزارة النفط بخططها الإنتاجية والتصديرية، الحساب الجاري. أما بالنسبة لسببية كجز الحساب الجاري بإتجاه جزز الموازنة فإن ورسم إستراتيجية جديدة لمعالجة الفساد المالي والإداري، وإزالة المبالغة في التقديرات زيادات الصادرات (X) سيؤدي إلى إنخاض العجز في الحساب الجاري أو (زيادة بالإعتاد على الأسس العلمية وخاصةً فيها يتعلق بالإنفاق الإستثمري (سالم، 2012، 318). وأخيراً يرى الباحثان أن إعتاد الدولة العينة الخمتارة سياسة مالية رشيدة من خلال الإهتام بالمشروعات الإنتاجية وزيادة النققات الرأسالية يؤدي الى تحسين الهيكل الإنتاجي وبالتالي تقليص العجزين في الحساب الجاري والموازنة العامة وخصوصاً الفائض في الحساب الجاري) وبما أن الصادرات النفطية يعتبر المصدر الرئيسي لإيرادات الدولة (T) وبالتالي فإن زيادة الصادرات سيؤدي إلى زيادة إيرادات الدولة وبالتالي زيادة الفائض (أو انخفاض العجز) في موازنة الدولة، وذلك بإفتراض ثبات كل من الإنغاق الحكوي (G) والواردات (M) ينتج عن ذلك تغيرات في الحساب الجاري على المدى البعيد. ستؤدي إلى تغيرات إيجابية في نس الإتجاه في الموازنة العامة. وبالتالي، يوجد هنالك علاقة سبية مزدوجة الإتجاه (BD ب CAD) بين كجز الموازنة ويجز الحساب 


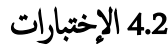

تم إستخدام المنهج الإحصائي القياسي الكمي، لتحليل وقياس أثر العلاقة المنبادلة ما بين المتغيرين، جزز الموازنة العامة (BD)، وجز الحساب الجاري (CAD)، بالإستعانة

ببضض الإختبارات الإحصائية بإستخدام برنامج (Eviews 8) لإجراء التحليل القياسي وتتكون الإختبارات من : 1. إختبار إستقرار البيانات (Stationary Test)، وفق إختبار ديكي فولر الموسع (ADF Test) 2. إختبار النكلم المشترك (Co-integration Test)، وفق إختبار .(Johansen Cointegration Test) 3. إختبارالسببية (Granger Causality Test). 4. تحليل نموذج متجه تصحيح الخطأ (Vector Error Correction Model). 5. إختبار عدم تجانس التباين (Heteroskedasticity Test). 1. إختبار إستقرارية البيانات (Stationarity Test) وفق إختبار ديكي فولر الموسع (ADF Test) I(1) أظهرت ننائُ إختبارات جذر الوحدة للسلاسل الزمنية بعد أخذ الفرق الأول لكل من جزز الموازنة العامة (BD) ويجز الحساب الجاري (CAD) أن بيانات المتغيرات ساكنة أي أن قيمة (t) المحسوبة أكبر من القيم الحرجة لجميع مستويات المعنوية (1\% و 5\% و 10\%) لذلك نرفض فرضية العدم مما يعني أن السلسلة مستقرة، وكما مبين بالجدول الاتي.
4. قياس إتجاه السببية بين جزز الموازتة والحساب الجاري في الإقتصاد العراقي للمدة

(2016-1988) 4.1 الموذج القياسي والبيانات لغرض بيان آثر العلاقة المتبادلة بين المتغيرات الإقتصادية (عجز الموازنة ويجز الحساب الجاري) في الإقتصاد العراقي بإستخدام السلاسل الزمنية خلال الفتزة (19882016)، سوف نستخدم نموذج قياسي يعتمد على بيانات سنوية رسمية صادرة من البنك المركزي العراقي تتضمن مدة الدراسة. ولأهداف تحتيق بعض التجانس في أحجام الأرقام القياسية المستخدمة في الدراسة، و تقليص تباين السلاسل الزمنية من جحة وتخفيض أثر المتغرات الشاذة من جحة أخرى، حولنا البيانات الأصلية إلى اللوغاريتات الطبيعية. وبما أن الميزان التجاري هو الفرق بين الصادرات والمستوردات ويأخذ قياً سالبة لا تقبل تحويلها للشكل اللوغاستيت، ولضرورات القياس الإقتادي تم قياس الميزان التجاري في هذه الدراسة بأخذ لوغاريتات نسبة الصادرات للمستوردات كما في دراسة (Koray \& McMillin,1999) و (Singh, 2002)، وكذلك بالنسبة لعجز الموازنة فقد تم قسمة الايرادات على النفقات وأخذ اللوغارتيم الطبيعي لها (السواعي والعزام، 2015، 4- (الع 103).

الجدول (3) : نتائج إختبار جذر الوحدة (Unit Root Test)

\begin{tabular}{|c|c|c|c|c|c|c|c|}
\hline النتاجُ & \multicolumn{3}{|c|}{ الفرق الأول (1St difference) } & \multicolumn{3}{|c|}{ المستوى (Level) } & \multirow[b]{2}{*}{ القيمة الحرجة } \\
\hline $\begin{array}{c}\text { مستقرة عند } \\
\text { I(1) }\end{array}$ & بدون قاطع وإتجاه & قاطع وإتجاه & 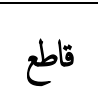 & بدون قاطع وإتجاه & قاطع وإتجاه & قاطع & \\
\hline & 2.65 & 33.4 & 69.3 & 56.2 & 32.4 & 69.3 & $\% 1$ \\
\hline & 1.95 & 58.3 & 97.2 & 95.1 & 58.3 & 97.2 & $\% 5$ \\
\hline & 60.1 & 22.3 & 62.2 & 60.1 & 22.3 & 62.2 & $\% 10$ \\
\hline $\mathrm{I}(1)$ & $8.04^{*}$ & $69.7^{*}$ & $7.86^{*}$ & 38.1 & 90.4 & 67.1 & $\mathrm{BD}$ \\
\hline $\mathrm{I}(1)$ & 4. $64^{*}$ & 3. $77^{*}$ & 3. $72^{*}$ & 1. 12 & 2. 31 & 1. 17 & CAD \\
\hline
\end{tabular}

المصدر : إعداد الباحثان بناء على المعطيات التالية : بيانات الجدول رقٌ (1)، التقارير السنوية للبنك المركزي- دائرة الأحصاء. * تدل على معنوية المتغيرات وقيمة (t) المحسوبة 
البالغة (20. 32) أكبر من القيمة الحرجة البالغة (15. 49) وإن القيمة العظىى التي تقدرب (17. 90) أكبر من القيمة الحرجة (14. 26) مما يدل ذلك على رفض فرضية العدم القائلة بعدم وجود أي متجهات للنكمل المشترك (None) بمستوى معنوية (5\%). مما دل على وجود متوافقة خطية ساكنة متكاملة بين عجز الحساب الجاري وعجز الموازنة، ومعنى ذلك أنه يوجد علاقة توازنية طوية الأمد بين المتغرين "ججز الموازنة (BD) وعجز الحساب الجاري (CAD)"، وإن هذه العلاقة لا تؤدي إلى ، الإنراف بينها عبر الزمن وإنما بالعكس يبديان سلوكاً متشابهاً ومثماثلاً.

2. ن نتجُج إختبار جوهانسن للنكلمل المشترك (Johansen Cointegration Test) يبين إختبار جوهانسن للنكامل المشترك إلى أنه هل هناك علاقة توازنية في الأجل الطويل بين متغيرات النموذج (جز الموازنة وجزالحساب الجاري) وذلك بالإعتماد على الإختبارين، إختبار الأثر (Trace) والقيمة العظمى (Maxima) Eigenvalue). ويمناز تطبيق إختبار جوهانسن ليس فقط في حالة وجود متغيرين في النموذج وإنما أيضاً عندما يحتوي النموذج على عدة متغيرات. ومع ذلك يفضل تطبيق إختبار جوهانسن في حالة متغيرين على إختبار أنجل وجرانجر ذات الخطوتين (الكسواني، 2001، 23). وتشير نتائج اختبار جوهانسن في الجدول رقٌ (4) ان قيمة إختبارالأثر الجدول (4) : إختبار النكامل المشترك لجوهانسن

\begin{tabular}{|c|c|c|c|c|c|}
\hline $\begin{array}{c}\text { Null Hypothesis } \\
\text { فرضية العدم }\end{array}$ & $\begin{array}{c}\text { القيم الخاصة } \\
\text { Eigenvalue }\end{array}$ & $\begin{array}{c}\text { الأثر } \\
\text { Trace }\end{array}$ & $\begin{array}{c}\text { القيمة العظمى } \\
\text { Max-Eigen }\end{array}$ & 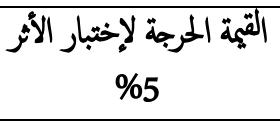 & القمة الحرجة لإختبار القيمة \\
\hline None* & 484715.0 & 32669.20 & 90193.17 & 49471.15 & 26460.14 \\
\hline At most 1 & 085891.0 & 424758.2 & 424758.2 & 841.3 & 841.3 \\
\hline
\end{tabular}
المصدر : إعداد الباحثان بناء على المعطيات التالية : بيانات الجدول رخ (1)، التقارير السنوية للبنك المركزي- دائرة الأحصاء

التباطئ (1) وهي المثلى في الجدول (6)، عجز الحساب الجاري يسبب عجز الموازنة

3. ن نتائُ اختبار جرانجر السبية (Granger Causality test)

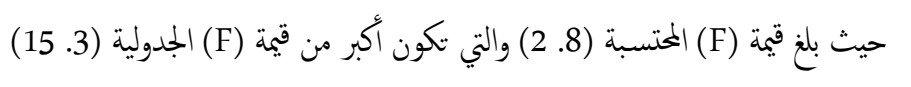
إضافة إلى أن قيمة (P) الإحتالية أقل من (5\%)، بينا عجز الموازنة يسبب عجز الحساب الجاري، في فترة النباطئ (4) والتي تكون قيمة (F) المحتسبة (4. 1)، نخلص من ذلك إلى وجود علاقة سبية ثنائية الإتجاه من جز الحساب الجاري إلى عجز الموازنة وكذلك بالعكس بمستوى معنوية(5\%). إختبار جرانجر السبية يوضح تحديد إتجاه السبية ما بين جزز الموازنة وعزز الحساب الجاري، أي بمعنى هل أن جز الموازنة يسبب عزز الحساب الجاري أم أن جز الحساب الجاري يسبب جزز الموازنة أو يوجد إتجاه ثنائية سبية أو لا يوجد علاقة سبية بين العجزين ؟. وتبين نتاجُ إختبار السبية بين العجزين في الجدول رقُ (5) أن العلاقة السبية موجودة بين يجز الحساب الجاري ويجز الموازنة، وأن سبية إتجاه عجز الحساب الجاري إلى عجز الموازنة أكثر تأثيراً وهذا ما يطابق فرضية البحث، فعندما نكون فنرة الجدول (5) : إختبار جرانجر السببية

\begin{tabular}{|c|c|c|c|c|}
\hline نوع العلاقة & F-Statistic & F Tables & Lags & Probability \\
\hline BDCAD يسبب لابCAD & 49554.1 & 3.15 & 1 & 2328.0 \\
\hline CAD يسبب BD & 20242.8 & 3. 15 & 1 & 0084.0 \\
\hline BDيسببCAD & 14928.4 & 3.15 & 4 & 0171.0 \\
\hline BDD لا يسبب BD & 68731.1 & 3. 15 & 4 & 2020.0 \\
\hline
\end{tabular}
المصدر : إعداد الباحثان بناء على المعطيات التالية : بيانات الجدول رڤٌ (1)، التقارير السنوية للبنك المركزي- دائرة الأحصاء في الأجل الطويل فن الأفضل تطبيق تقدينموذج تصحيح الخطأ (VEC)، وذلك الك Vector Error Correction ) بحليل قياسي لنموذج متجه تصحيح الخطأ لغرض إختبار التوازن في الأجل الطويل وبيان ديناميكية الأمد القصير بين العجزين، (VECM) (Model بما أن نتيجة إختبار جوهانسن للنكامل المشترك إيجابية ويوجد إرتباط ما بين العجزين لاسيا أن النموذج (VEC) من أكثر الناذج إستخداماً لتوضيح العلاقة الديناميكية بين 
متغرين فقط. لكن قبل تطبيق وتحليل نموذج (VEC) لمتغيرات يجز الموازنة ويزز فترة الإبطاء المثلى هي الواقعة في (1) والتي تكون قيمة (AIC) و (SC) أقل الحساب الجاري يجب تحديد عدد فترات الإبطاء المثلى لمتغرات الدراسة. ونلاحظ من قيمة، وقد طبقنا إختبار النكمل المشترك لجوهانسن عند فترة الإبطاء المثلى (1 :

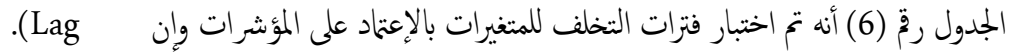
الجدول (6) : عدد التخلفات او التأخرات لنموذج (VEC) لمتغيرات الدراسة

\begin{tabular}{|c|c|c|c|c|c|c|}
\hline Lag & Log L & LR & FPE & AIC & SC & HQ \\
\hline 0 & $945226.4-$ & NA & 005849.0 & 534248.0 & 631025.0 & 562116.0 \\
\hline 1 & 04363.16 & $37.13413^{*}$ & $0.001586^{*}$ & $-0.772587^{*}$ & $-0.482257^{*}$ & $-0.688982^{*}$ \\
\hline 2 & 75979.19 & 003025.6 & 001634.0 & -750753.0 & $266869.0-$ & -611412.0 \\
\hline 3 & 74539.22 & 363574.4 & 001798.0 & $672722.0-$ & 004714.0 & -477645.0 \\
\hline
\end{tabular}

المصدر : إعداد الباحثان بناء على المعطيات التالية : بيانات الجدول رڤ (1)، التقارير السنوية للبنك المركزي- دائرة الأحصاء. * تشير إلى عدد فنرات الإبطاء المثلى، وكل إختبار عند مستوى 5\%

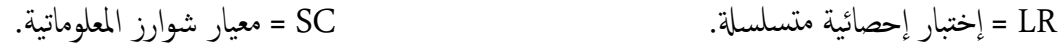

$$
\begin{aligned}
& \text { FPE } \\
& \text { = AIC }
\end{aligned}
$$

طردية وإرتباط بين العجزين، ولغرض معنوية وتأثير المتغيرات في الأمد القصير سوف نطبق تصحيح الخطأ (VEC) على كل متغير لوحده، وكما يلي : أ. نابُج وتحليل تقدير نموذج تصحيح الخطأ (VEC) في حالة عجز الحساب الجاري كتغير ثابع تدل نتائج الملحق (1) في الجدول (10) أن قيمة C(1) سالبة (0. 34-) ما يدل على وجود علاقة سبية بين العجزين وأثر المتغير المستقل ججز الموازنة (BD) على المتغير التابع جزز الحساب الجاري (CAD) في الاجل القصير، أي أن التغيرات التي تحصل في جز الموازنة سوف تستجيب عجز الحساب الجاري بنسبة (34\%) في المدى القصير، وأيضاً قيمة دربن واتسن (2. 26) يدل على عدم وجود مشكلة الإرتباط الذاتي، ومع أن قيمة (F) المحتسبة قليلة (1. 97)، بالإضافة إلى أن قيمة (R) تساوي (33\%)، لكن يبقى وجود العلاقة السبية للحصول على قيمة (1) سالبة (0. 34).

\section{ب. نتاجُ وتحليل تثدير نموذج تصحيح الخطاً (VEC) في حالة جزز الموازنة كتغير تابع}

نلاحظ في الملحق (2) الجدول (11) أن قيمة (1) أيضاً سالبة والتي تساوي (1. 08-)، لذا يوجد علاقة سببية ومعنوية جزز الحساب الجاري في الثأثيرعلى جز الموازنة في الأجل القصير، وهذا يدل على أن التغيرات التي تحصل في (CAD) سوف تستجيب (BD) بنسبة (108\%) في الأجل القصير، بالإضافة إلى أن قيمة دربن

\section{5. نتاجُ وتحليل متجه تصحيح الخطاً (VEC)} يوضح الجدول رق (7) نتائُ التحليل القياسي لمتجه تصحيح الخطأ (VEC)، ما يبين أن نسبة جزز الموازنة إلى الناتج المحلي الإجالي (GDP) لسنة سابقة أو سنتين سابقتين ترتبط بعلاقة طردية مع سبة عجز الموازنة للسنة الحالية، أي أن زيادة (1\%) من نسبة العجز للموازنة لسنة سابقة أو سنتين سوف يؤدي إلى زيادة نسبة العجز إلى (GDP) الحالية بنسبة (0. 28) و (0. 46) على التوالي، أما نسبة العجز للموازنة إلى (GDP) لسنة سابقة ترتبط بعلاقة عكسية مع نسبة جز الحساب الجاري للسنة الحالية، أي أن زيادة (1\%) من جز الموازنة لسنة سابقة سوف يؤدي إلى إنخاض نسبة جز الحساب الجاري بنسبة (0. 17)، ولكن هناك علاقة طردية ما بين نسبة جزز الموازنة إلى (GDP) لسنتين سابقتين مع نسبة عزز الحساب الجاري الحالي، بمعى زيادة (1\%) من نسبة جزز الموازنة لسنتين سابقتين يؤدي إلى ارتفاع نسبة عجز الحساب الجاري بمقدار (0. 13)، أما عند زيادة (1\%) من نسبة جزز الحساب الجاري لسنة سابقة يؤدي إلى إرتفاع نسبة جز الموازنة الحالية وجز الحساب الجاري الحالي بمقدار (0. 22)، (0. 24) على التوالي، وإن زيادة (1\%) من جزز (CAD) لسنتين سابتين يؤدي إلى إنخفاض يجز (BD) و (CAD) الحالي بعقدار (0. 50) و (0. 27) على التوالي. مما يدل الجدول رقّ (7) على وجود علاقة 
6. نتاجُ وتحليل اختبار عدم تجانس التباين (Heteroskedasticity Test) في حالة

\section{عزز الحساب الجاري كتغير تابع}

إن فرضية العدم وفق إختبار عدم تجانس التباين (تغيير قيمة تباين حد الخطأ Ui، بجيث تزداد هذه القيمة بزيادة قيمة المتغير المستقل) تشير إلى عدم وجود مشكلة عدم

Prob. Chi- تجانس التباين أو حد الخطأ، ومن الجدول رق (8) نلاحظ أن قيمة (Square التي تنص على عدم وجود مشكلة عدم تجانس حد الخطأ وهذا يدل على أن التغير في المتغير المستقل (BD) لا يؤدي إلى زيادة تباين المتغير التابع (CAD) أي ثبات تباين حد الخطأ
واتسون (2. 2) تدل على خلو النموذج من مشكة الإرتباط الناتي، وكذلك أن قيمة (F) المقدرة البالغة (3. 26) معنوية، مما يدل ذلك على الإستجابة الكبيرة لعجز الموازنة نتيجة التغيرات التي تحدث في يجز الحساب الجاري كتنير مستقل، وهذا ما يتطابق مع ما ورد في فرضية وأهداف البحث. الجدول (7) : نموذج متجه تصحيح الخطأ (VEC)

\begin{tabular}{|c|c|c|}
\hline Error Correction & $\mathrm{D}(\mathrm{LBD})$ & $\mathrm{D}(\mathrm{LCAD})$ \\
\hline \multirow{3}{*}{$\mathrm{C}$} & 0.022477 & 0.0000126 \\
\hline & (0. 05099) & (0. 01208) \\
\hline & [44084 .0 ] & [00104 .0 ] \\
\hline \multirow{3}{*}{$\mathrm{D}(\operatorname{LBD}(-1))$} & 0.280930 & -0.172453 \\
\hline & $(0.32851)$ & (0. 18913) \\
\hline & [85517 .0 ] & {$\left[\begin{array}{lll}-91184 & .0\end{array}\right]$} \\
\hline \multirow{3}{*}{$\mathrm{D}(\mathrm{LBD}(-2))$} & 0.456687 & 0.133135 \\
\hline & $(0.19982)$ & $(0.11504)$ \\
\hline & [28550.2] & [15730.1 ] \\
\hline \multirow{3}{*}{$\mathrm{D}(\operatorname{LCAD}(-1))$} & 0.223182 & 0.238344 \\
\hline & $(0.36819)$ & (0. 21198) \\
\hline & [60615 .0 ] & [12439.1 ] \\
\hline \multirow{3}{*}{$\mathrm{D}(\operatorname{LCAD}(-2))$} & -0.497504 & -0.269523 \\
\hline & $(0.35416)$ & (0. 20390) \\
\hline & {$\left[\begin{array}{lll}-40473.1\end{array}\right]$} & [32186 .1-] \\
\hline R-squared & 449677.0 & 330744.0 \\
\hline F-statistic & 268461.3 & 976787.1 \\
\hline Log likelihood & 826136.1 & 18180.16 \\
\hline Akaike AIC & 321066.0 & -783216.0 \\
\hline Schwarz SC & 611396.0 & -492886.0 \\
\hline
\end{tabular}

المصدر : إعداد الباحثان بناء على المعطيات التالية : بيانات الجدول رخٌ (1)، التقارير السنوية للبنك المركزي- دائرة الأحصاء القوس ( ) يشير إلى الخطأ المعياري، والقوس [ ] يشير إلى اختبار 
الجدول (8) : إختبار عدم تجانس التباين (Heteroskedasticity Test)

\begin{tabular}{|c|c|c|c|}
\hline F-statistic & 980103.0 & Prob. F(6, 47) & 4655.0 \\
\hline Obs*R-squared & 145188.6 & Prob. Chi-Square(6) & 4071.0 \\
\hline Scaled explained SS & 421823.2 & Prob. Chi-Square (6) & 8771.0 \\
\hline
\end{tabular}

المصدر : إعداد الباحثان بناء على المعطيات التالية : بيانات الجدول رخ (1)، التقارير السنوية للبنك المركزي- دائرة الأحصاء

تساوي (Obs*R-squared)

بفرضية العدم التي تنص على عدم وجود مشكلة عدم تجانس حد الخطأ وهذا يدل

على أن التغير في المتغر المستقل (CAD) لا يؤدي إلى زيادة تباين المتغير التابع

(BD)

\section{7. تنابُج وتحليل إختبار عدم تجانس التباين (Heteroskedasticity Test) في حالة}

عزز الموازنة كمثغير ثابع قيمة حد الخطأ Ui، بحيث تزداد هذه القيمة بزيادة قيمة المتغير المستقل) تشير إلى عدم وجود مشكلة عدم تجانس النباين أو حد الخطأ، ومن الجدول رقٍ (9) نلاحظ أن قيمة

الجدول (9) : إختبار عدم تجانس التباين (Heteroskedasticity Test)

\begin{tabular}{|c|c|c|c|}
\hline F-statistic & 994836.1 & Prob. F(6, 47) & 0853.0 \\
\hline Obs*R-squared & 96045.10 & Prob. Chi-Square(6) & 0896.0 \\
\hline Scaled explained SS & 47192.21 & Prob. Chi-Square (6) & 0015.0 \\
\hline
\end{tabular}

المصدر : إعداد الباحثان بناء على المعطيات التالية : بيانات الجدول رثٌ (1)، التقارير السنوية للبنك المركزي- دائرة الأحصاء

أ. وفق إختبار غرانجر السبية يوجد علاقة طردية سبية مزدوجة الإتجاه بين عجز

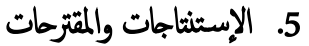

الموازنة ويزز الحساب الجاري. وأن سبية جزز الحساب الجاري باتجاه الموازنة اكثر

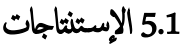

معنوية. يمكن تكثيف أهم النتائُ التي توصل إليها الباحثان بالآتي :

ب. وجود علاقة طويلة الأجل بين العجزين حسب إختبار التكمل المشترك 1. تدني معدلات النمو الإقتصادي بسبب زيادة النفقات التشغيلية وإنخفاض الإنفاق الإستثماري الإنتاجي مما خلق ذلك إختلالات هيكلية إنتاجية في الإقتصاد العراقي، لجوهانسن. إضافةً إلى أن الموازنة العامة والحساب الجاري تتحكم بها عوامل خارجية (التذبذبات ت. طبقا لنموذج تقدير تصحيح الخطأ يتضح : 1. أن نسبة عزز الموازنة إلى الناتج المللي الإجلالي (GDP) لسنة سابقة أو سنتين في أسعارالسوق النفطية) مما يضعف السياسة الإقتصادية المالية. 2. قيام الدولة لتمويل العجز من خلال الإقتاض الخارجي أدى إلى تفامٍ الضغوط سابقتين ترتبط بعلاقة طردية مع نسبة جزز الموازنة للسنة الحالية، أما نسبة العجز التضخمية خاصةً لكون الجهاز الاإنتاجي للدولة ضعيف، إضافةً إلى أن زيادة تدفقات لموازنة إلى (GDP) لسنة سابقة ترتبط بعلاقة عكسية مع نسبة عجز الحساب الإحتياطيات النقدية لعلاج مشكلة التضخم أدت إلى إنخفاض النمو لعدم إستغلال الجاري للسنة الحالية. هذه الإحتياطات في تحفيز القطاع الخاص وبالتالي خلق مصادر أخرى لايرادات 2. وجود علاقة طردية ما بين نسبة جز الموازنة إلى (GDP) لسنتين سابقتين مع سبة عجز الحساب الجاري الحالي. وأيضاً علاقة طردية ما بين نسبة جز الحساب الدولة، والتي نجمت عن ذلك لعدم التنسيق بين السياسة المالية والنقدية.

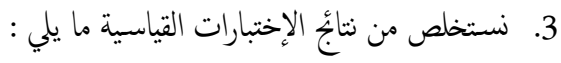


ج. قيام البنك المركزي بتوجيه ودعز تمويل القطاع المصرفي نخو الأنشطة المنتجة اقتداءً بدول جنوب شرق آسيا في تنشيط القدرات الإنتاجية المحلية والصناعات

الموجتمة للتصدير.

ح. تأهيل القطاع النفطي بتكنولوجيا متطورة ومتقدمة وإستخدام تقنيات حديثة في صناعة النفط والغاز مع كادر متدرب في مواقع العمل أو في الخارج وذلك لتنية قدراتهم لتطبيق أحسن الطرق في المجال النفطي فضلاً عن إستغلال إمكنيات الطاقة على أحسن وجه بإعتبارنا بلد نقطي مما يؤدي هذا إلى رفع التنمية الإجتاعية والإقتصادية في

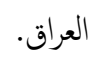

خ. ضرورة إصلاح النظام الضريبي، كونه أحد المصادر المهمة لزيادة إيرادات الدولة ولتقليص جزز ميزانية الحكومة.

\section{قائمة المصادر}

الثقارير ومواقع الاتتزيت

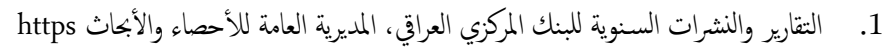

://www. cbi. iq

المصادر باللغة العربية

1. البنك الدولي، (2015)، الموجز الإقتصادي الفصلي لمنطقة الشرق الأوسط وشال أفريقيا -

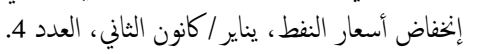

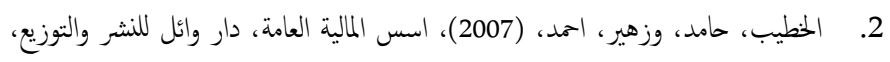

عان، الاردن.

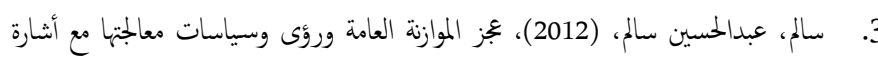

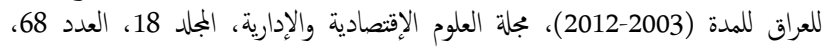

بغداد.

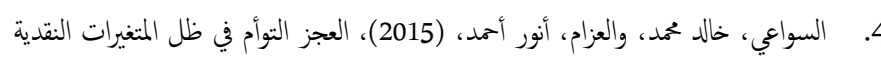

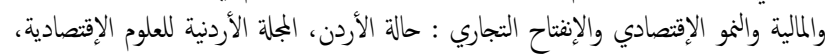

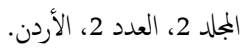

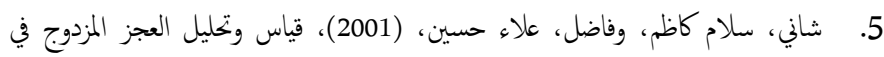

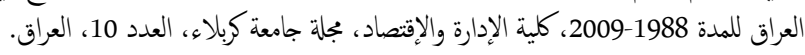

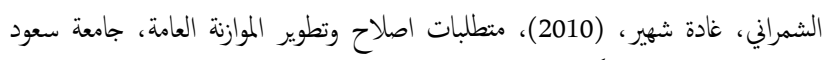

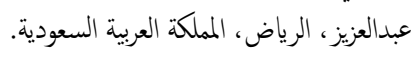

7.

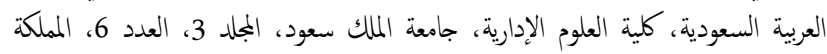

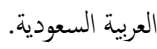

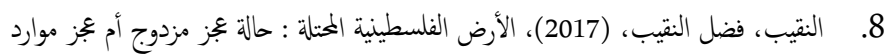

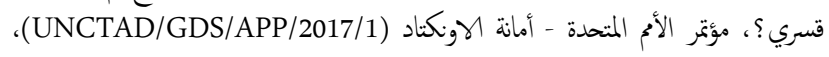

نيويورك وجنيف. فئكي

9. وردة، موساوي، (2016)، تحليل العلاقة بين مجز الموازنة والتوازن الخارجي في الاقتصاد

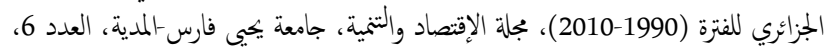

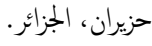

الجاري لسنة سابقة أدى إلى ارتفاع نسبة جزز الموازنة الحالية وجزالحساب الجاري الحلالي.

3. أن النغرات في جز الحساب الجاري تؤثر بشكل كير في تغيرات عزز الموازنة في

الأجل القصير ، أي زيادة (1\%) من (CAD) يؤدي إلى زيادة (108\%) من

5.2

على ضوء الإستنتاجات التي توصل إليها الباحثان يمكن عرض المقترحات التالية : 1. ضرورة علاج الإختلال في ميزان المدفوعات من خلال تطبيق السياسات

النقدية والمالية الملائمة والتي تؤدي إلى حالة وجود معدل نمو الصادرات أعلى من معدل نمو في الواردات حتى ينخض العجز في الميزان التجاري تدريياً. لذلك يستوجب على الإقتصاد العراقي تنويع صادراته بالإعتماد على سياسة إقتصادية ملائمة تسمح له برسم سياسة تحصينية تمكنه من مواجتة الصدمات الخارجية. 2. مساهمة القروض الخارجية في خلق وتوسيع الطاقات الإنتاجية وليس في تمويل الإستهلاك الجاري.

3. إعتاد سياسة مالية تسعى إلى تحقيق النمو والتنمية المستدامة في البلد من خلال إنتهاج إستراتيجية خخطة بشكل متقن وإعتاد برامج ودورات علمية وإستخدام تكنولوجيا حديثة، لتطوير قطاعات إقتصادية حيوية للدولة ولتحقيق ذلك ينبني : أ. تحفيز الأفراد على زيادة إدخاراتهم بغية زيادة التمويل الإستثماري مع العمل على ستل تخفيض العجز الملالي للدولة وبالتالي رفع الإدخار الوطني. ب. دع القطاع الزراعي من خلال إعتاد برامج وإسترتيجية تكنولوجية تشمل جميع جوانب البيئة الزراعية بما في ذلك الموارد البشرية، الاراضي والمياه والبنية التحتية، وزيادة المنتجات الزراعية. ت. توسيع القطاع الصناعي لعلاج إختلالات هيكلية إنتاجية مما يقلص الإستيرادات في البداية ثم يليه زيادة الصادرات. ث. تطوير القطاع السياحي من خلال تنفيذ مشاريع تنموية خدمية وملاهي ترفيية ومائية خاصة في إقليم كوردستان الذي تتميز باراضيه ومناطقه الجبلية، وكذلك تنمية السياحة الدينية.

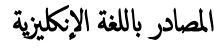


6. Khalid, A. M. \& Guan, T. W. (1999), Causality tests of budget and current account deficits : Cross-country comparisons, Empirical Economics.

7. Kim, C. H. \& D. Kim, (2006), does Korea have Twin Deficits? Applied Economics Letters, 13.

8. Magazzino, C. , (2012), The Twin Deficits phenomenon : evidence from Italy, Journal of Economic Cooperation and Development.

9. Saleh, A. S. , Nair, M. \& Agalewatte, T. (2005), the Twin Deficits Problem in Sri Lanka : An Econometric Analysis, South Asia Economic Journal, 6.

10. Vamvoukas, G. (1999), the Twin Deficits Phenomenon : Evidence from Greece, Applied Economics, 31.

11. Yanik, Y. (2006), the Twin Deficits Hypothesis : an Empirical Investigation, Graduate School of Social Sciences, Turkish.
1. Alasrag, H. , (24. April 2010), the role of small and medium in job creation in the Arab countries, Munich Personal RePEc Archive (MPRA), No. 22300. enterprises.

2. Alrubaie, F. A, (2010), Analysis of changes : in the orientation of economic policy in Iraq, MPRA Paper No. 28371 posted 25, January $201106: 57$ UTC.

3. Çelik, S. \& Deniz, P. , (2007). An Empirical Investigation of Twin Deficit Hypothesis for Six Emerging Countries, JEL Classification : F32; H62.

4. Evenson RE. \& Westphal LE. , (1995). Technological change and technology strategy In : Behrman $\mathrm{J}$ and Srinivasan $\mathrm{TN}$, eds. Handbook of Development Economics Volume 3A. Elsevier. Amsterdam.

5. Hany, E. Sara, M. \& Hugh, M. (2010), Twin Deficits : New evidence from an Arab world, Newcastle University Business School.

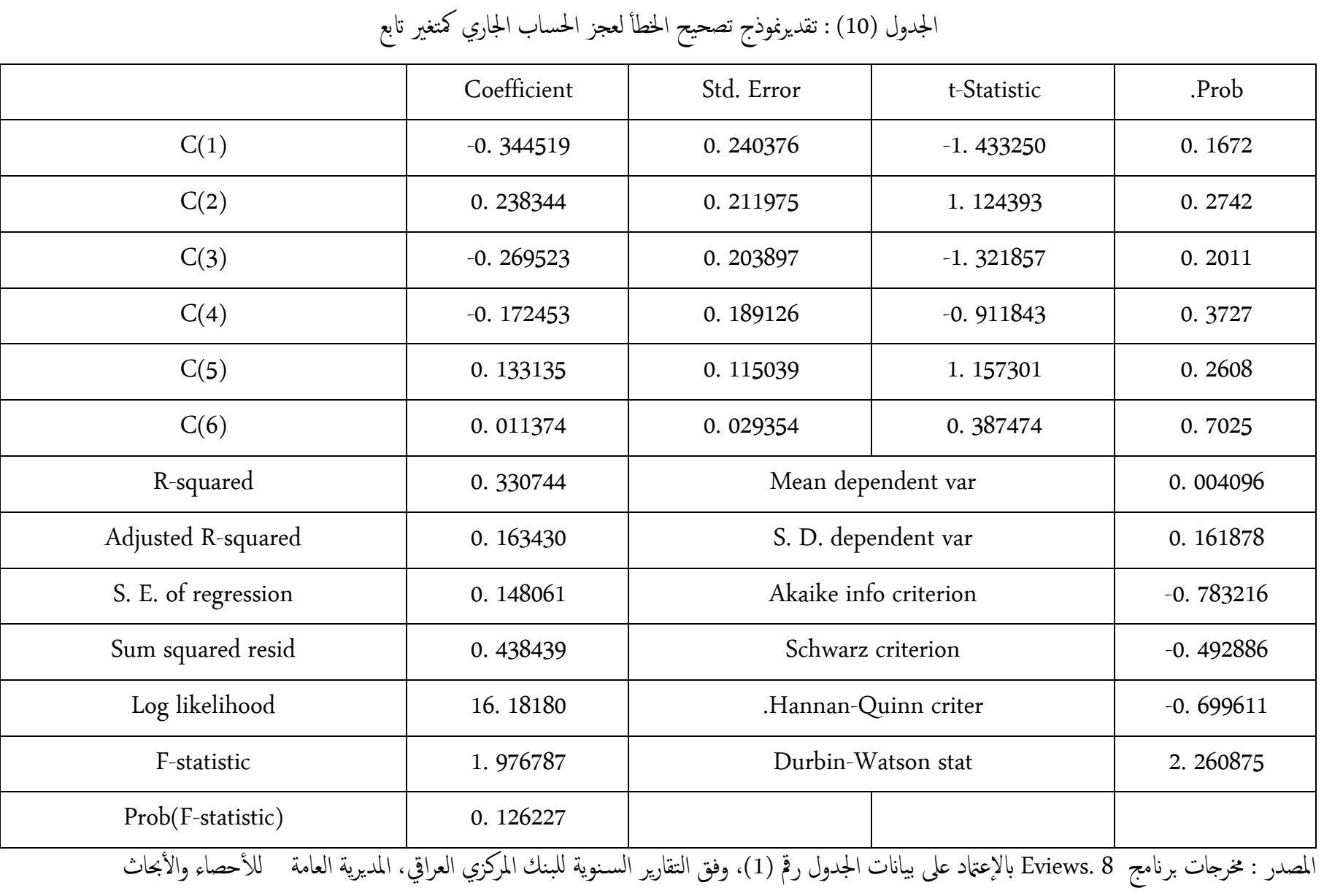


الملحق (2)

الجدول (11) : تقديرموذج تصحيح الخطأ لعجز الموازنة كتغير تابع

\begin{tabular}{|c|c|c|c|c|}
\hline & Coefficient & Std. Error & $\mathrm{t}$-Statistic & .Prob \\
\hline $\mathrm{C}(1)$ & -1.084798 & 0.415908 & -2.608268 & 0.0168 \\
\hline $\mathrm{C}(2)$ & 0.280930 & 0.328506 & 0.855175 & 0.4026 \\
\hline $\mathrm{C}(3)$ & 0.456687 & 0. 199820 & 2. 285495 & 0.0333 \\
\hline $\mathrm{C}(4)$ & 0.223182 & 0.368195 & 0.606153 & 0.5512 \\
\hline $\mathrm{C}(5)$ & -0.497504 & 0.354163 & -1.404730 & 0.1754 \\
\hline$C(6)$ & 0.022477 & 0.050987 & 0.440835 & 0.6641 \\
\hline $\mathrm{R}$-squared & 0.449677 & \multicolumn{2}{|c|}{ Mean dependent var } & 0.005071 \\
\hline Adjusted R-squared & 0.312096 & \multicolumn{2}{|c|}{ S. D. dependent var } & 0.310076 \\
\hline S. E. of regression & 0.257177 & \multicolumn{2}{|c|}{ Akaike info criterion } & 0.321066 \\
\hline Sum squared resid & 1. 322796 & \multicolumn{2}{|c|}{ Schwarz criterion } & 0.611396 \\
\hline Log likelihood & 1. 826136 & \multicolumn{2}{|c|}{.Hannan-Quinn criter } & 0.404671 \\
\hline F-statistic & 3. 268461 & \multicolumn{2}{|c|}{ Durbin-Watson stat } & 2. 206209 \\
\hline Prob(F-statistic) & 0.025610 & & & \\
\hline
\end{tabular}

المصدر : مخرجات برنامج 8 . بviews. 